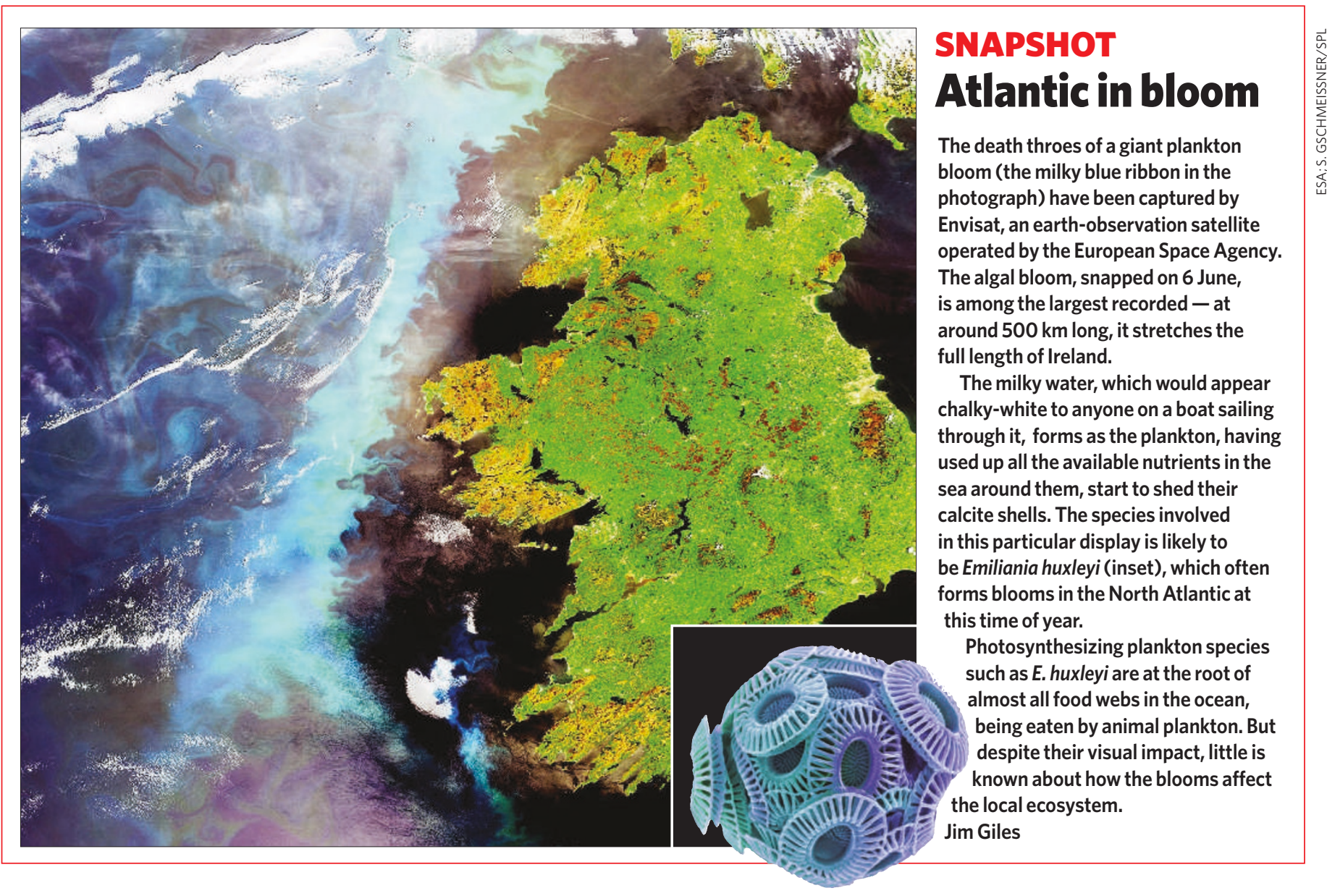

\title{
US satellite system loses climate sensors
}

\section{WASHINGTON DC}

Climate scientists are scrambling to find new backers for atmospheric sensors they had hoped would fly on board a US militarycivilian polar satellite system. Last week, government officials scrubbed three planned instruments - which would have measured key climate variables - in an effort to get the long-troubled project back on budget and schedule.

First proposed in 1994, the National Polarorbiting Operational Environmental Satellite System (NPOESS) had been touted as a onestop shop for both military and civilian needs to gather data on global weather. It was meant to save money and avoid duplication between three government agencies - the US Department of Defense, the National Oceanic and Atmospheric Administration (NOAA), and NASA. Originally slated to cost US $\$ 6.5$ billion and launch in 2008, the project is going to cost upwards of US\$11 billion and will not launch until at least 2013.
Under the new design, the programme "will have fewer satellites and less sensors, while costing more money", NOAA administrator Conrad Lautenbacher told a congressional hearing on 8 June.

The cutbacks come as part of a defence department review of the programme, required by law because it was so far over budget. Five key sensors have been temporarily removed, three of which are related to climate science.

"They decided to de-scope everything not related to short-term weather forecasting," says programme scientist P. K. Bhartia, who works on an ozone sensor for the satellites. "At this point, we're really confused as to what will happen."

If industry, a university or a research agency decides to pay for the instruments directly, they - or stripped-down versions of them may be placed back onto the NPOESS satellites. In the meantime, climate scientists are left wondering whether their sensors will ever get to fly.
"Absolutely, we're quite disappointed," says Ron Isaacs, executive vice-president of the Massachusetts-based company Atmospheric Environmental Research, which helped design another sensor that was axed. That instrument, Isaacs says, would have served some unique functions, such as measuring soil moisture.

The European Meteop satellites could work with NPOESS satellites to obtain some of the necessary data. But US officials are concerned about how much of the data would actually be shared - especially information useful for the military.

Still, many in Congress support the NPOESS programme, even as it balloons in cost. "We have to make this work," says congressman Sherwood Boehlert (Republican, New York), chairman of the House Committee on Science. "At some point that word 'operational' has to mean more than adding a vowel to the acronym." Jacqueline Ruttimann 